\title{
Cardiovascular response to short-term fasting in menstrual phases in young women: an observational study
}

\author{
Kumiko Ohara ${ }^{1,2}$, Yoshimitsu Okita ${ }^{3}$, Katsuyasu Kouda ${ }^{4}$, Tomoki Mase ${ }^{5}$, Chiemi Miyawaki ${ }^{6}$ \\ and Harunobu Nakamura ${ }^{*}$
}

\begin{abstract}
Background: Menstrual cycle-related symptoms are an important health issue for many women, and some may affect cardiac autonomic regulation. In the present study, we evaluated the cardiovascular and physiological stress response to 12-h short-term fasting in the menstrual phases of healthy young women.

Methods: We performed a randomized crossover study. Subjects were seven female university students (age: $22.3 \pm 1.0$ years). The experiments comprised four sessions: meal intake in the follicular phase, meal intake in the luteal phase, fasting in the follicular phase, and fasting in the luteal phase. All subjects participated in a total of four experimental sessions during two successive phases (follicular and luteal phase in the same menstrual cycle, or luteal phase and follicular phase in the next menstrual cycle) according to a randomized crossover design. R-R intervals were continuously recorded before and after meals, and power spectral analysis of heart rate variability was performed. Other physiological data were obtained before and 20,40,60, and 80 min after meal intake or after the corresponding time point of meal intake (fasting in the follicular or luteal phase).

Results: Heart rate decreased during fasting in the follicular and luteal phases. High frequency power increased during fasting in the follicular and luteal phases. In addition, salivary cortisol concentrations decreased during fasting in the luteal phase.

Conclusions: In the present study, short-term fasting resulted in higher parasympathetic activity and lower cortisol levels in the luteal phase in these young women. These results indicate a possibility to produce an anti-stress effect in the luteal phase, which may reduce menstrual symptoms.
\end{abstract}

Keywords: Menstrual cycle, Women's health, Dietary bihavior, Fasting, Anti-stress

\section{Background}

Menstrual cycle-related symptoms may include psychological symptoms, such as irritation or depressed feelings, or physical symptoms, such as headache or stomach ache in the premenstrual [1-3] and menstrual phases of the menstrual cycle $[4,5]$. According to the estimation of World Health Organization (WHO), 199 million women had premenstrual syndrome as of 2010, which was $5.8 \%$ of all women [6]. Previous reports also showed about $10 \%$ of women had premenstrual syndrome, and about 70-90 \%

\footnotetext{
*Correspondence: hal@kobe-u.ac.jp

${ }^{1}$ Graduate School of Human Development and Environment, Kobe University, Kobe, Japan

Full list of author information is available at the end of the article
}

of women experienced menstrual cycle-related symptoms [7-13]. This also applies to Japanese women [14-16]. In addition to physiological characteristics, menstrual cyclerelated symptoms affect health-related quality of life [17]. According to an epidemiological study, average scores of students with premenstrual syndrome were significantly lower in all domains of quality of life [18, 19]. Therefore, alleviation of these symptoms is expected to contribute to improvement of quality of life.

Previous studies showed that symptoms are severe during the luteal phase $[11,20,21]$. The venous oxygenation index is decreased in the late luteal phase in premenstrual syndrome subjects [22]. In addition, stressful situations have been reported to be associated with the 
occurrence of menstrual cycle-related symptoms [23]. Stress is known to affect cardiovascular changes, which are usually related to autonomic nervous system activity changes [24]. Spectral analysis of heart rate variability (HRV) provides a sensitive, non-invasive measure of cardiac autonomic regulation. Two main frequency components of HRV have been demonstrated, low frequency (LF: 0.04-0.15 Hz) reflecting both sympathetic and parasympathetic nervous system activity, and high frequency (HF: $0.15-0.40 \mathrm{~Hz}$ ) reflecting the activity of the parasympathetic nervous system [25]. Consequently, the LF-to-HF (LF/HF) ratio represents the sympathovagal balance [25]. In previous studies, HF was lower in the luteal phase than the follicular phase [26-31], and LF/HF was higher in the luteal phase than the follicular phase [26-29, 32], indicating increased sympathetic nervous activity in the luteal phase and increased parasympathetic nervous activity in the follicular phase. Moreover, sympathetic nervous activity is stronger in women with severe menstrual symptoms than in those with less severe symptoms [33].

Dietary restriction (DR), also known as calorie restriction, is a restriction of total food from ad libitum feeding. There is some evidence that restricting single micronutrients or organic compounds, such as sodium or caffeine, alleviates menstrual cycle-related symptoms [34, 35]. Pellizzer et al. reported that reduced dietary fat intake increased parasympathetic activity in women [36]. Fasting is one form of DR. The anti-stress effects of fasting were demonstrated in men, whereby short-term fasting (12 h) increased parasympathetic domain activity while meal intake activated sympathetic domain activity [37]. However, there is little evidence of the anti-stress effects of shortterm fasting on menstrual cycles. Some studies reported that 2.5- to 3.5-day fasting suppresses the reproductive axis [38-40], which means a fasting period is critical. All of these factors lead us to hypothesize that 12-h shortterm fasting may increase parasympathetic activity in the luteal phase.

Therefore, in the present study, we evaluated the cardiac autonomic regulation and physiological stress response to 12-h short-term fasting during each menstrual phase in young women.

\section{Methods}

\section{Subjects}

The subjects were recruited from the local university with no incentives. We enrolled seven healthy female students who satisfied the inclusion and exclusion criteria for entry into the study. The inclusion criteria were female gender and age of 20 to 24 years. The exclusion criteria were past and current smoking, alcoholism, high-performance athletes, medication use, oral contraceptive use, irregularity of menstrual cycle, parity, and body mass index $\geq 25 \mathrm{~kg} / \mathrm{m}^{2}$. All subjects were carefully informed about the purpose and potential risks of this experiment, and all gave written informed consent to participate in this study. The study protocol was approved by the Human Ethics Committee of the Graduate School of Human Development and Environment, Kobe University.

\section{Experimental procedure}

The experiments were conducted from February 2012 to February 2014. The experimental procedure is shown in Fig. 1a and b. All subjects participated in a total of four experimental sessions during two successive phases (follicular and luteal phase in the same menstrual cycle, or luteal phase and follicular phase in the next menstrual cycle) according to a randomized crossover design. In the first menstrual cycle, the first and second sessions were conducted. In the second menstrual cycle, the third and fourth sessions were conducted. In the first and second sessions in the first menstrual cycle, the subjects were randomly assigned to each trial: (1) the meal intake trial or (2) the fasting trial. After a 12-h overnight fast, subjects assigned to the meal intake trial were served a test meal, and those assigned to the fasting trial continued fasting for a further $2 \mathrm{~h}$ (total $14 \mathrm{~h}$ ). If the first session was conducted in the follicular phase, the second session was conducted in the luteal phase in the same menstrual cycle. If the first session was conducted in the luteal phase, the second session was conducted in the follicular phase in the next menstrual cycle. Third and fourth sessions were also conducted in the same way as the first and second sessions. In the first and second sessions, the subjects were randomly assigned to the meal intake trial or the fasting trial. In the third and fourth session, the subjects were assigned to other than the trial assigned in each follicular or luteal phase in the first and second sessions. Subjects were determined as being in the follicular phase or luteal phase based on the occurrence of menstruation and ovulation. Ovulation was recognized by a surge in luteinizing hormone detected using two selfexamination kits for luteinizing hormone (L-check FT; Nipro Co., Ltd, Osaka, Japan and P-check; Mizuho Medy Co., Ltd, Saga, Japan).

On the day before testing, the subjects in both the meal intake trial and the fasting trial finished their meals by $21: 00 \mathrm{~h}$ and went to sleep before 24:00 $\mathrm{h}$. They abstained from drinks containing caffeine, food containing capsaicin, alcohol, and sports activity for $24 \mathrm{~h}$ prior to each testing day. After overnight fasting, each subject arrived at the laboratory between 08:00 $\mathrm{h}$ and 08:30 $\mathrm{h}$ and rested in the supine position for $20 \mathrm{~min}$ in an environmentally controlled room (temperature, $23-26{ }^{\circ} \mathrm{C}$; relative humidity, 50-60\%). After resting, baseline physiological and psychological assessments were conducted. Saliva samples were collected at the same time, and stored at $-25{ }^{\circ} \mathrm{C}$ for assessment of salivary cortisol levels. The physiological assessments included an electrocardiogram, 


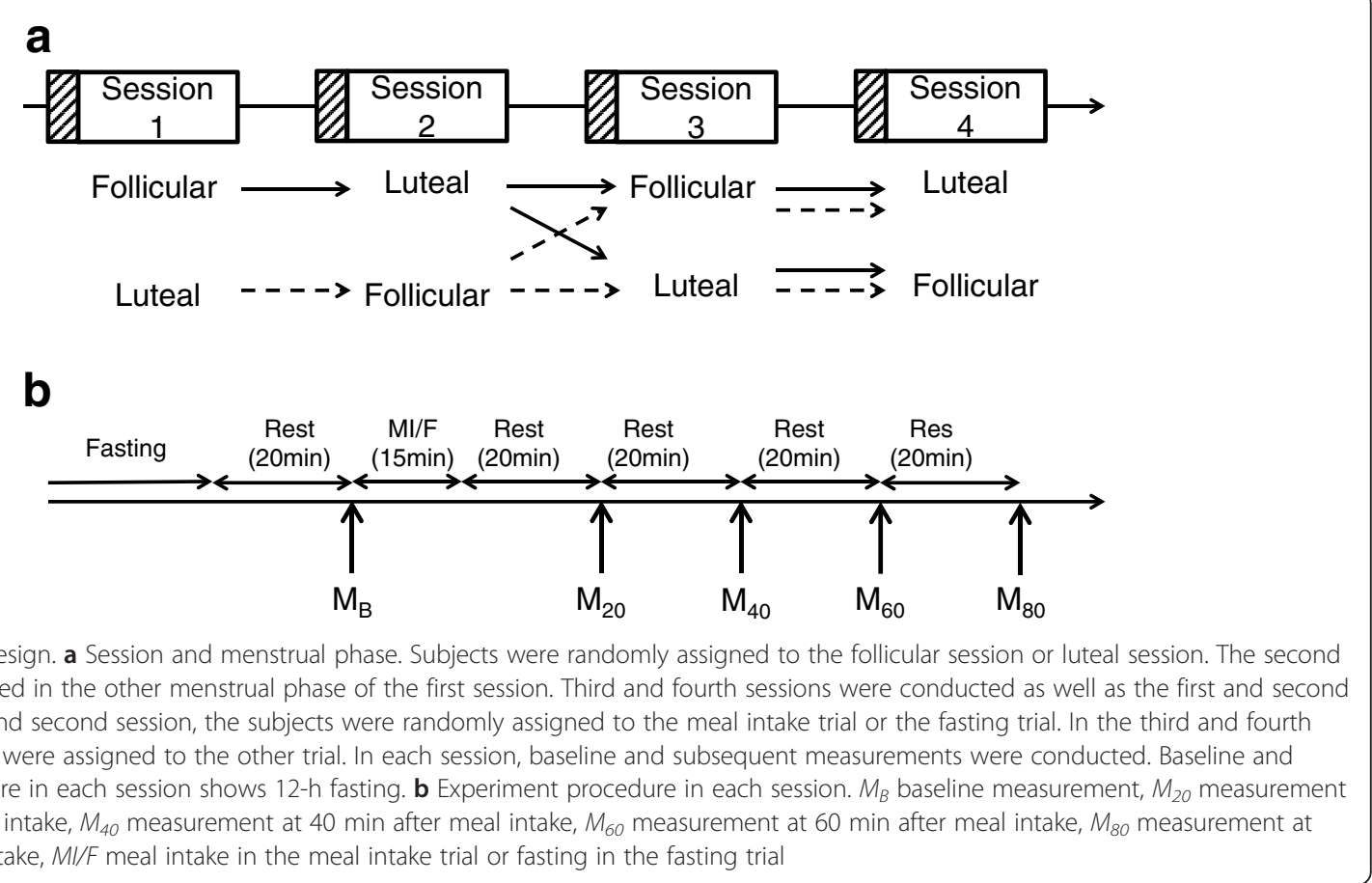

and measurement of systolic blood pressure (SBP) and diastolic blood pressure (DBP). SBP and DBP were measured by the Riva-Rocci-Korotkoff method using a digital manometer (GP-303S, Parama-Tech Co., Ltd, Fukuoka, Japan). A test meal was served for the meal intake trial at 09:50 $\mathrm{h}$, and the subjects finished eating by 10:05 h. Postprandial physiological and psychological data and a saliva sample were obtained at 20 , 40, 60, and $80 \mathrm{~min}$ after meal intake. For the fasting trial, a test meal was not served, but physiological and psychological data and a saliva sample were obtained 20,40,60, and $80 \mathrm{~min}$ after the corresponding time point of intake of food in the meal intake trial.

\section{Composition of nutrients and energy content in each trial}

The meal for the experiment consisted of $81 \mathrm{~g}$ of bread made from bread flour and white sugar, $26 \mathrm{~g}$ of ham, and $200 \mathrm{~g}$ of orange juice, which together contained $395 \mathrm{kcal}$ of energy, $15.5 \mathrm{~g}$ of protein, $11.3 \mathrm{~g}$ of fat, $57.5 \mathrm{~g}$ of carbohydrate (energy \%: protein/carbohydrate/fat 15/62/23), and $0.8 \mathrm{~g}$ of sodium. The overall energy contained in the meal and the energy proportions of carbohydrate, protein, and fat were determined according to the mean intake of food in females in their 20s reported in the National Nutrient Survey in Japan [41]. These meals were served at $36.0{ }^{\circ} \mathrm{C}$. Meal temperature was measured using a noncontact thermometer (Thermo-Hunter, model PT-2LD; Optex Co., Otsu, Japan). All drinks were provided at room temperature. In the fasting trial, each subject continued fasting throughout the experiment for a further $2 \mathrm{~h}$.

\section{Heart rate variability}

The R-R intervals, the time interval between two consecutive $R$ waves in the electrocardiogram, were continuously recorded before and after meals by an ambulatory electrocardiograph monitor (Active Tracer AC-301A; GMS Inc., Tokyo, Japan) with a sampling rate of $1 \mathrm{kHz}$. Power spectral analysis of HRV was performed using a 16th-order autoregressive model [42] by Kubios HRV analysis software 2.0 (Biomedical Signal and Medical Imaging Analysis Group, Department of Applied Physics, University of Kuopio, Finland) [43].

We analyzed low frequency power (LF: $0.04-0.15 \mathrm{~Hz}$ ) and high frequency power (HF: $0.15-0.40 \mathrm{~Hz}$ ) as HRV parameters. LF power reflects sympathetic and parasympathetic modulation of the heart, whereas HF power primarily reflects parasympathetic modulation of the heart [25]. LF and HF power were computed for each minute of the 5-min R-R data [44]. The LF/HF ratio was calculated as an index of sympathovagal balance [25]. The mean of each 1-min HRV was used for statistical analysis.

\section{Salivary cortisol assay}

All frozen samples were thawed, mixed, and centrifuged at $3000 \times \mathrm{g}$ for $10 \mathrm{~min}$ at room temperature. Samples were analyzed in duplicate with a competitive 
immunoassay specifically validated for the quantitative measurement of salivary cortisol (Salimetrics LLC, State College, PA, USA). The calibration range was $0.012-3.0 \mu \mathrm{g} / \mathrm{dL}$.

\section{Statistical analysis}

Data are shown as means \pm standard error. The Student's $t$ test was used to detect differences between the trials at baseline. A two-way repeated-measures analysis of variance (ANOVA) was used to investigate the effects of meal conditions (eating or fasting), the effects of time, and interaction effects between condition and time on physiological parameters. The Bonferroni test was used for post-hoc analysis. Effect sizes are reported as generalized eta squared $\left(\eta_{G}^{2}\right)$, which allows direct comparison of within- and between-subjects designs [45], and interpreted according to Cohen's recommendation of .02 for a small effect, .13 for a medium effect, and .26 for a large effect [46]. Statistical analysis was performed using SPSS Statistics 19 (IBM Inc., Tokyo, Japan). A $P$ value less than 0.05 was considered statistically significant.

\section{Results}

\section{Baseline data}

The mean age \pm standard deviation of subjects was 22.3 \pm 1.0 years. The subjects' height, body weight, and body mass index were $158.0 \pm 3.8 \mathrm{~cm}, 50.7 \pm 4.6 \mathrm{~kg}$, and 20.5 $\pm 2.1 \mathrm{~kg} / \mathrm{m}^{2}$, respectively. All subjects completed a meal in approximately $15 \mathrm{~min}$ in each session. Table 1 shows baseline data for physiological characteristics. There was no difference in the baseline data.

\section{Physiological responses}

Changes in heart rate (HR) in the follicular phase are shown in Fig. 2a. Two-way repeated-measures ANOVA showed that time and meal condition had a significant main effect on HR (time, $P<0.001, \eta_{G}^{2}=0.060$; meal, $\left.P<0.001, \eta_{G}^{2}=0.118\right)$. There was also a significant interaction effect between time and meal condition for $\operatorname{HR}\left(\mathrm{F}[4,24]=6.34, P<0.001, \eta_{G}^{2}=0.056\right.$ ). Post-hoc testing showed that HR in the eating trial was significantly increased at $20,40,60$, and $80 \mathrm{~min}$ after the meal compared with baseline (20 $\mathrm{min}, P=0.026$; $40 \mathrm{~min}$,

Table 1 Physiological characteristics at baseline in each trial $(n=7)$

\begin{tabular}{lccccc}
\hline & \multicolumn{2}{l}{ Follicular phase } & & \multicolumn{2}{l}{ Luteal phase } \\
\cline { 2 - 3 } & Fasting trial & Eating trial & & Fasting trial & Eating trial \\
\hline HR (beats/min) & $58.1 \pm 8.1$ & $56.3 \pm 6.5$ & & $59.7 \pm 9.2$ & $60.9 \pm 12.8$ \\
SBP $(\mathrm{mmHg})$ & $98.7 \pm 13.9$ & $100.4 \pm 10.6$ & & $97.6 \pm 9.4$ & $101.4 \pm 8.3$ \\
DBP $(\mathrm{mmHg})$ & $59.9 \pm 9.1$ & $62.5 \pm 8.2$ & & $60.1 \pm 7.4$ & $60.1 \pm 6.2$ \\
\hline
\end{tabular}

$H R$ heart rate, $S B P$ systolic blood pressure, $D B P$ diastolic blood pressure Data are mean \pm standard deviation

There was no difference in baseline characteristics
$P=0.004 ; 60 \mathrm{~min}, P=0.017 ; 80 \mathrm{~min}, P=0.045)$. There was no significant change in HR in the fasting trial. In addition, HR was significantly higher in the eating trial than in the fasting trial at 20,40,60, and $80 \mathrm{~min}$ after the meal (20 $\mathrm{min}, P=0.005 ; 40 \mathrm{~min}, P=0.029 ; 60 \mathrm{~min}$, $P<0.001 ; 80 \mathrm{~min}, P=0.005)$. Changes in $\mathrm{HR}$ in the luteal phase are shown in Fig. 2b. Two-way repeatedmeasures ANOVA showed that time and meal condition had a significant main effect on HR (time, $P=$ 0.002, $\eta_{G}^{2}=0.039$; meal, $P=0.012, \eta_{G}^{2}=0.120$ ). There was also a significant interaction effect between time and meal condition with HR (F $[4,24]=5.79, P=0.002$, $\eta_{G}^{2}=0.030$ ). Post-hoc testing showed that $\mathrm{HR}$ in the eating trial was significantly increased at 20,60 , and $80 \mathrm{~min}$ after the meal compared with baseline $(20 \mathrm{~min}$, $P=0.014 ; 60 \mathrm{~min}, P=0.037 ; 80 \mathrm{~min}, P=0.034)$. HR in the fasting trial was significantly higher at $80 \mathrm{~min}$ after the meal compared with $20 \mathrm{~min}$ after the meal $(P=$ 0.029). In addition, HR was significantly higher in the eating trial than in the fasting trial at 20,40, and $60 \mathrm{~min}$ after the meal $(20 \mathrm{~min}, P=0.001 ; 40 \mathrm{~min}, P=$ 0.009; 60 min, $P=0.025$ ).

Changes in SBP in the follicular and luteal phases are shown in Fig. 3a and b. There was no significant main effect or interaction effect for SBP.

Changes in DBP in the follicular phase are shown in Fig. 4a. Two-way repeated-measures ANOVA showed that time had a significant main effect on DBP $\left(P=0.03, \eta_{G}^{2}=\right.$ 0.019). There was also a significant interaction effect between time and meal condition for DBP $(F[4,24]=5.48$, $\left.P=0.003, \eta_{G}^{2}=0.058\right)$. Post-hoc testing showed that DBP was significantly higher in the fasting trial than in the eating trial at 40,60 , and $80 \mathrm{~min}$ after the meal (40 min, $P=0.014 ; 60$ min, $P=0.049 ; 80 \mathrm{~min}, P=0.03$ ). Changes in DBP in the luteal phase are shown in Fig. $4 \mathrm{~b}$. Two-way repeated-measures ANOVA showed that time had a significant main effect on DBP $(P=0.037$, $\left.\eta_{G}^{2}=0.040\right)$. There was no significant interaction effect between time and meal condition for DBP. Post-hoc testing showed that DBP was significantly higher in the fasting trial than in the eating trial at $40 \mathrm{~min}$ after the meal.

\section{HRV}

Changes in the LF/HF ratio in the follicular and luteal phases are shown in Fig. $5 \mathrm{a}$ and b. Two-way repeatedmeasures ANOVA showed that meal condition had a significant main effect on the LF/HF ratio in the luteal phase $\left(P=0.038, \eta_{G}^{2}=0.095\right)$. Post-hoc testing showed that the LF/HF ratio was significantly higher in the eating trial than in the fasting trial at $60 \mathrm{~min}$ after the meal $(P=0.015)$. There were no other main or interaction effects for the LF/HF ratio.

Changes in HF power in the follicular phase are shown in Fig. 6a. Two-way repeated-measures ANOVA showed 

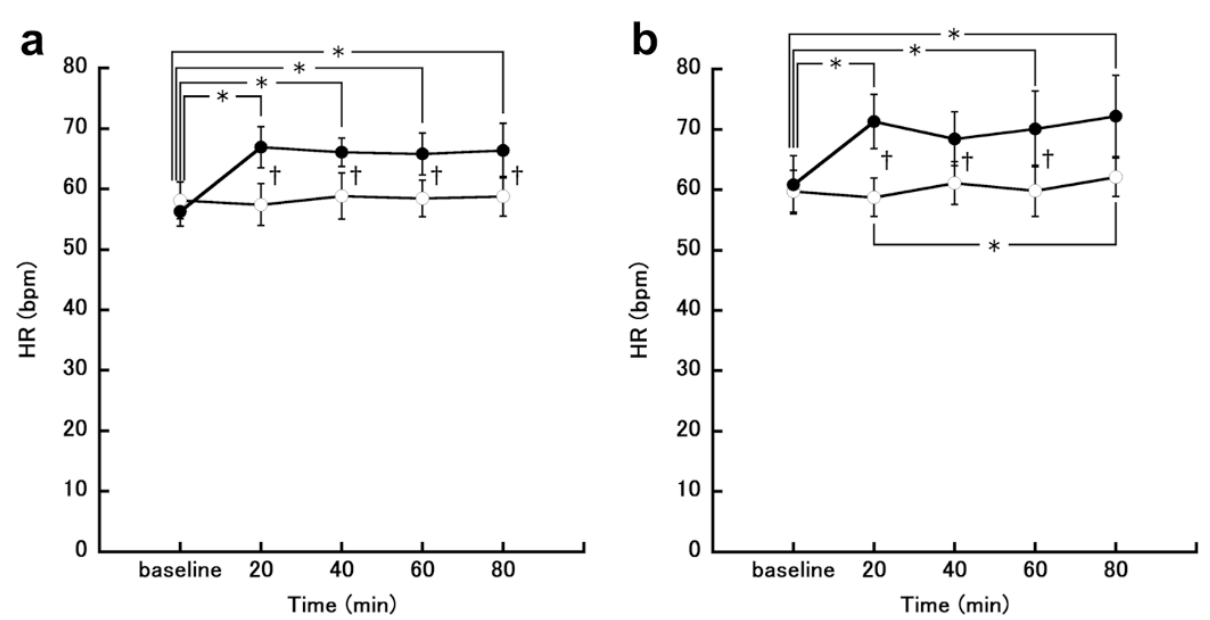

Fig. 2 Changes in heart rate (HR). a Follicular phase. $\mathbf{b}$ Luteal phase. The eating trial is shown by closed circles $(\bullet ; n=7)$ and the fasting trial is shown by open circles $(0 ; n=7) .{ }^{*} P<0.05$, comparison between time points in the eating or fasting session; ${ }^{\dagger} P<0.05$, comparison between the eating and fasting trials

that meal condition had a significant main effect on HF power in the follicular phase $\left(P=0.047, \eta_{G}^{2}=0.088\right)$. There was also a significant interaction effect between time and meal condition for $\operatorname{HF}\left(\mathrm{F}[4,24]=2.83, P=0.047, \eta_{G}^{2}=\right.$ 0.061). Post-hoc testing showed that HF power was significantly higher in the fasting trial than in the eating trial at 60 and $80 \mathrm{~min}$ after the meal $(60 \mathrm{~min}, P=0.038 ; 80 \mathrm{~min}$, $P=0.018$ ). Changes in HF power in the luteal phase are shown in Fig. 6b. Two-way repeated-measures ANOVA showed that time had a significant main effect on HF power in the luteal phase $\left(P=0.042, \eta_{G}^{2}=0.060\right)$. There was also a significant interaction effect between time and meal condition for HF $\left(\mathrm{F}[4,24]=3.09, P=0.035, \eta_{G}^{2}=\right.$ $0.071)$.

\section{Salivary cortisol}

Changes in salivary cortisol concentrations in the follicular phase are shown in Fig. 7a. Two-way repeatedmeasures ANOVA showed that time had a significant main effect on salivary cortisol concentrations in the follicular phase $\left(P=0.003, \eta_{G}^{2}=0.065\right)$. There were no other main or interaction effects in salivary cortisol concentrations. Changes in salivary cortisol concentrations in the luteal phase are shown in Fig. 7b. Two-way repeated-measures ANOVA showed that time and meal condition had a significant main effect on salivary cortisol concentrations (time, $P=0.015, \eta_{G}^{2}=0.176$; meal, $\left.P=0.028, \eta_{G}^{2}=0.319\right)$. There was also a significant interaction effect between time and meal condition for salivary
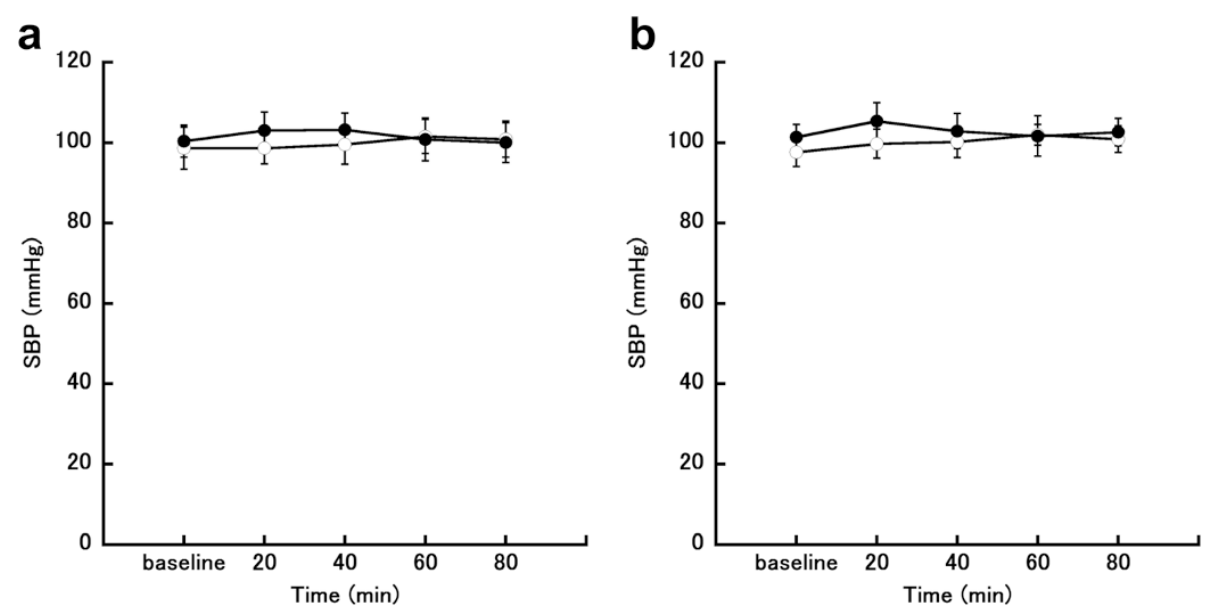

Fig. 3 Changes in systolic blood pressure (SBP). a Follicular phase. b Luteal phase. The eating trial is shown by closed circles $(\bullet ; n=7)$ and the fasting trial is shown by open circles $(0 ; n=7)$ 

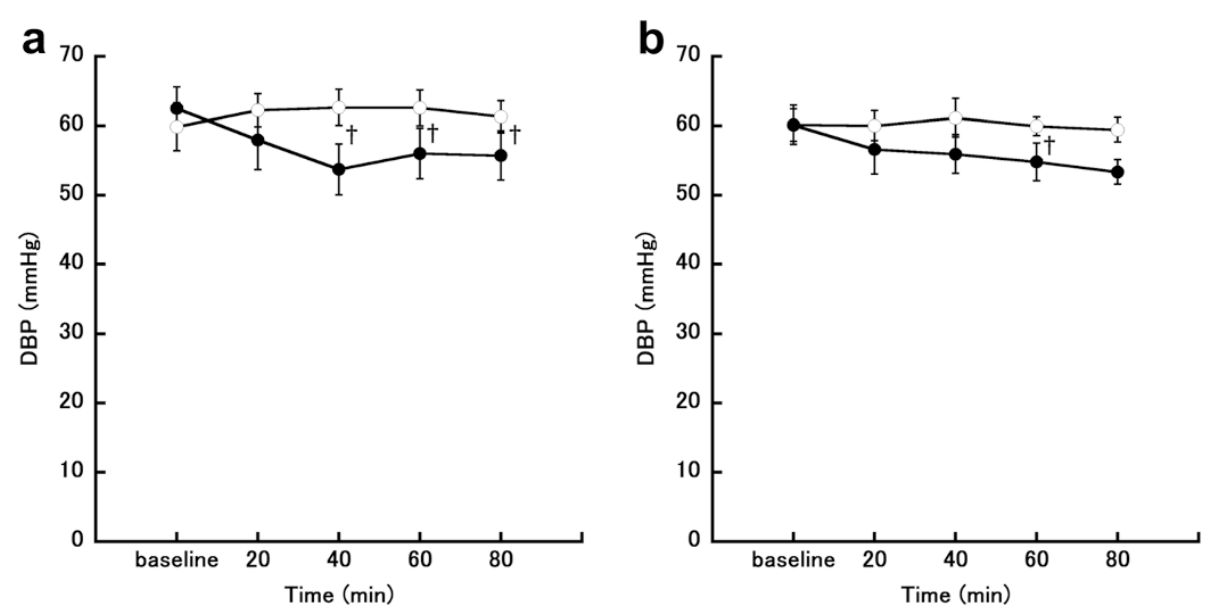

Fig. 4 Changes in diastolic blood pressure (DBP). a Follicular phase. $\mathbf{b}$ Luteal phase. The eating trial is shown by closed circles $(\bullet ; n=7)$ and the fasting trial is shown by open circles $(0 ; n=7){ }^{\dagger} P<0.05$, comparison between the eating and fasting trials

cortisol concentrations $\left(\mathrm{F}[4,24]=3.45, P=0.023, \eta_{G}^{2}=\right.$ 0.066). Post-hoc testing showed that salivary cortisol concentrations were significantly higher in the eating trial than in the fasting trial at 20,40 , and $80 \mathrm{~min}$ after the meal (20 $\min , P=0.011 ; 40 \mathrm{~min}, P=0.011 ; 80 \mathrm{~min}, P=0.037$ ).

\section{Discussion}

In the present study, we evaluated the cardiovascular response to the short-term fasting in the different menstrual phases. The main results were as follows: (1) HR was decreased during fasting in the follicular and luteal phases; (2) HF power was increased during fasting in the follicular and luteal phases; and (3) salivary cortisol concentrations were decreased during fasting in the luteal phase.
In the present study, during fasting, HR was decreased and HF power was increased in the follicular and luteal phases. Generally, HF power indicates parasympathetic activity [25]. In addition, HR increases in the sympathetic dominant phase and decreases in the parasympathetic dominant phase [47]. Therefore, the present results in the fasting state indicated that parasympathetic activity was dominant. In male subjects, 12 -h fasting results in dominance of parasympathetic activity compared with food intake [37]. Conversely, little is known about the effects of short-term fasting such as 12-h fasting in women. Herbert et al. reported that $24 \mathrm{~h}$ of fasting induced higher heart rate, and lower HF, indicating increased sympathetic nervous system activity [48]. In addition, 72-h fasting increased norepinephrine, dopamine, and heart rate, and decreased cardiac vagal
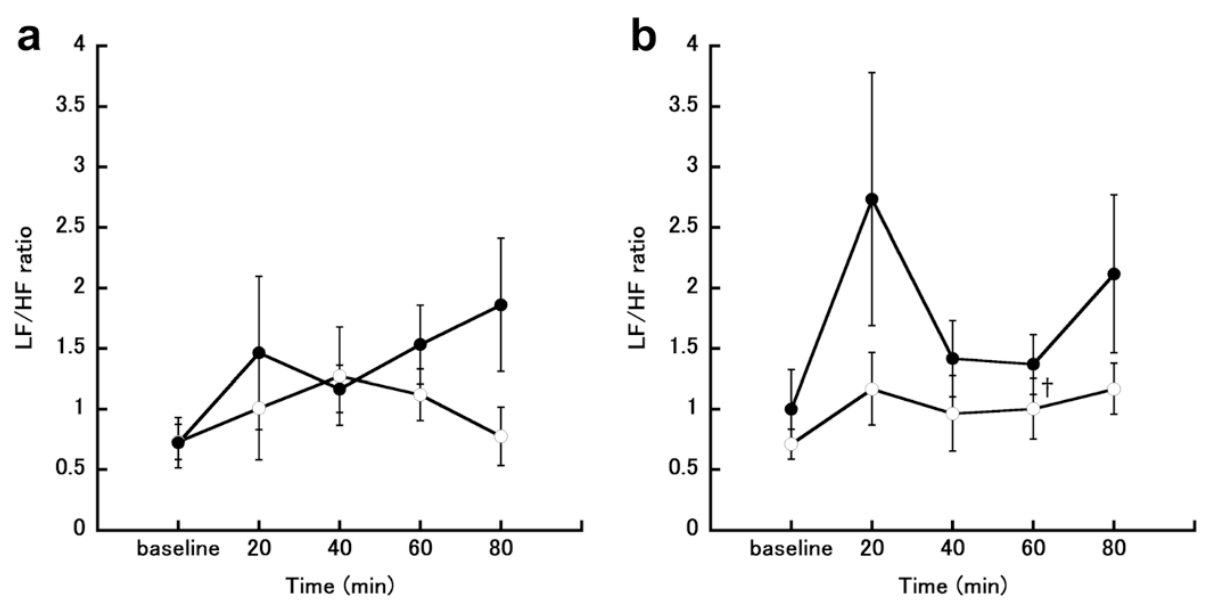

Fig. 5 Changes in low frequency/high frequency ratio (LF/HF). a Follicular phase. b Luteal phase. The eating trial is shown by closed circles $(\bullet ; n=7)$ and the fasting trial is shown by open circles $(0 ; n=7) .{ }^{\dagger} P<0.05$, comparison between the eating and fasting trials 

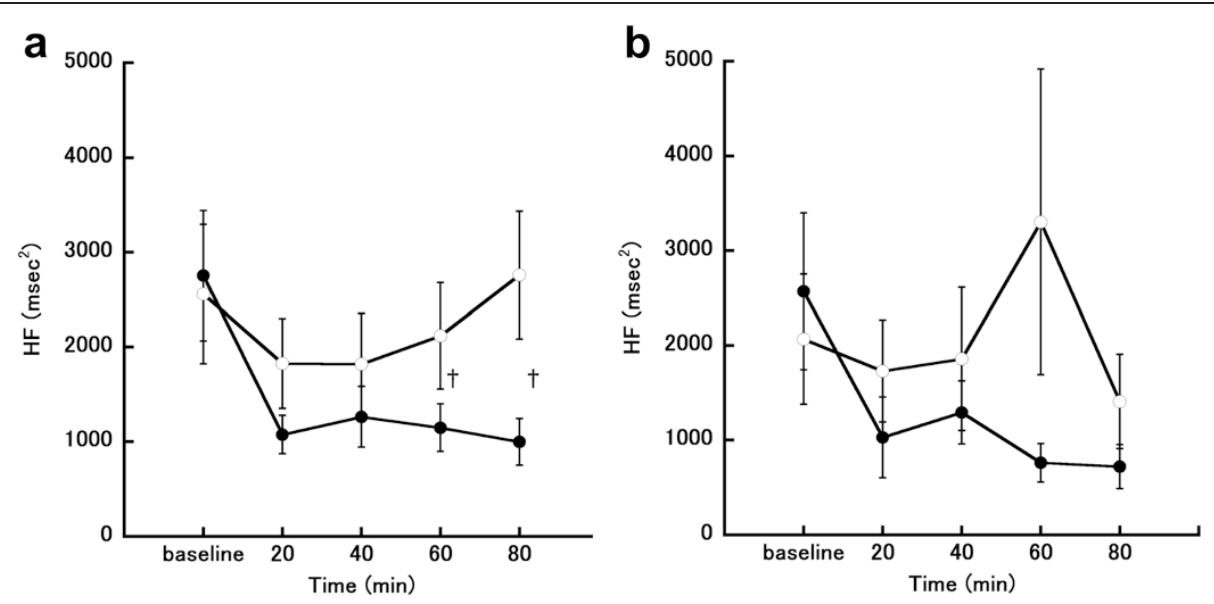

Fig. $\mathbf{6}$ Changes in high frequency (HF). a Follicular phase. b Luteal phase. The eating trial is shown by closed circles $(\bullet ; n=7)$ and the fasting trial is shown by open circles $(0 ; n=7){ }^{\dagger} P<0.05$, comparison between the eating and fasting trials

modulation [49]. These results are inconsistent with our results. The reason for this discrepancy is unclear, but it may be a result of the difference in fasting duration.

In our study, interestingly, salivary cortisol concentrations were decreased during fasting in the luteal phase. Salivary cortisol is reflected by stressful situations. Cortisol concentrations increase during stressful situations and decrease during low-stress situations [50]. The use of a potent laboratory stress protocol reproducing a job interview (e.g., the Trier Social Stress Test [51]) activates the sympathetic-adrenomedullary system and the hypothalamic-pituitary-adrenocortical axis [52]. Both systems interact in managing the adaptive response to stressful events, and biomarkers of these systems can be evaluated non-invasively in saliva. This method allows repeated samples in a short time [53-55]. Activation of the hypothalamic-pituitary-adrenocortical axis induces the secretion of cortisol, which stimulates mobilization of the energy required to overcome the stressor. Therefore, cortisol is considered as the main biomarker in stress research [50]. Based on these facts, the present results indicate that fasting leads to less stressful conditions. These results are consistent with the present results of HR or autonomic activity. Reduction of stress has also been shown in previous reports in some experiments in rats or rhesus monkeys [56, 57] and men [37], but not in women. Interestingly, in the present study, antistress effects were shown in female subjects in the luteal phase. This suggests that DR has an anti-stress effect on the luteal phase. Menstrual cycle-related symptoms are severe during the luteal phase [58], and stress is related to these symptoms [23]. Therefore, DR is also expected to reduce these symptoms and increase quality of life in women.
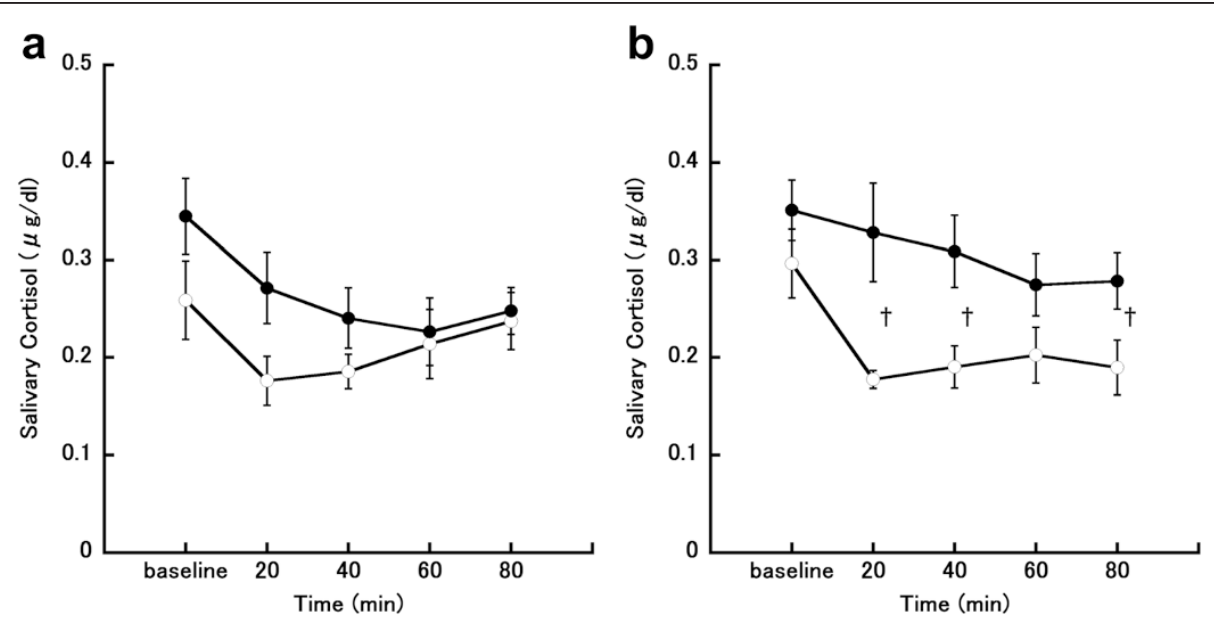

Fig. 7 Changes in salivary cortisol concentrations. a Follicular phase. b Luteal phase. The eating trial is shown by closed circles $(\bullet ; n=7)$ and the fasting trial is shown by open circles $(0 ; n=7) .{ }^{\dagger} P<0.05$, comparison between the eating and fasting trials 


\section{Limitations}

There are some limitations to this study. First, the meals used in the present study had a complicated nutrient content, whereas fasting was a simple experiment. Therefore, the underlying mechanism for the present results is still unclear. The autonomic nervous system engages in maintenance of homeostasis by cooperation with other regulatory systems. Therefore, the underlying mechanism in this study may be explained from the viewpoint of whole-body coordination in future studies. Second, we conducted experiments with a controlled setting, which may be different from a non-controlled setting. Third, we did not investigate the long-term effects of fasting. Long-term effects of food intake are ultimately necessary to clarify the influence of daily lifestyles in humans. Therefore, further studies are required to determine this issue. Fourth, the present study does not refer to longer-term stress. Future studies need to test repeated $12-\mathrm{h}$ fasting to verify the effects of fasting on long-term stress. Repeated 12-h fasting may not only affect long-term stress but also address the feasibility and safety of fasting, and the influence of resumed eating on stress levels.

\section{Conclusions}

We evaluated the cardiovascular response to short-term fasting in each menstrual phase in healthy young females. HR is decreased during fasting in the follicular and luteal phases. HF power is increased during fasting in the follicular and luteal phases. Additionally, salivary cortisol concentrations are decreased during fasting in the luteal phase. These results suggest a possibility of short-term fasting to produce anti-stress effects in the luteal phase in women, which may lead to reduced menstrual symptoms. Twelve-hour fasting is an easy method to practice in daily life without help from a health professional. To that end, further study needs to clarify the mechanisms underlying these findings and to verify the long-term effects of fasting.

\section{Competing interests}

The authors declare that they have no competing interests.

\section{Authors' contributions}

$\mathrm{KO}$ conceived the study, participated in the study design, conducted the experiment, analyzed the data, and drafted the manuscript. YO participated in the study design, provided advices on the experimental protocol and the data analysis, and reviewed the manuscript. KK participated in the study design, and provided advices on the data management and statistical analysis. TM participated in the study design and the data interpretation. CM participated in the study design and the experiment. HN participated in the study design and the experiment, and critically reviewed the manuscript. All authors provided revisions. All authors read and approved of the final version of the article.

\section{Acknowledgements}

This work was supported in part by Grants-in-Aid for JSPS Fellows

(13 J02216) from the Japan Society for the Promotion of Science.

\section{Author details}

${ }^{1}$ Graduate School of Human Development and Environment, Kobe University, Kobe, Japan. ${ }^{2}$ Research Fellow of the Japan Society for the Promotion of Science, Tokyo, Japan. ${ }^{3}$ Graduate School of Science and Technology, Shizuoka University, Hamamatsu, Japan. ${ }^{4}$ Department of Public Health, Kinki University Faculty of Medicine, Osaka-Sayama, Japan. ${ }^{5}$ Department of Childhood Education, Kyoto Seibo College, Kyoto, Japan. ${ }^{6}$ Department of Early Childhood Education, Heian Jogakuin (St. Agnes') College, Kyoto, Japan.

Received: 27 January 2015 Accepted: 14 August 2015

Published online: 28 August 2015

\section{References}

1. Steiner M. Premenstrual syndrome and premenstrual dysphoric disorder: guidelines for management. J Psychiatry Neurosci. 2000;25:459-68.

2. Wittchen HU, Becker E, Lieb R, Krause P. Prevalence, incidence and stability of premenstrual dysphoric disorder in the community. Psychol Med. 2002;32:119-32.

3. Biggs WS, Demuth RH. Premenstrual syndrome and premenstrual dysphoric disorder. Am Fam Physician. 2011;84:918-24

4. Deligeoroglou E. Dysmenorrhea. Ann N Y Acad Sci. 2000;900:237-44.

5. French L. Dysmenorrhea. Am Fam Physician. 2005;71:285-91.

6. Vos T, Flaxman AD, Naghavi M, Lozano R, Michaud C, Ezzati M, et al. Years lived with disability (YLDs) for 1160 sequelae of 289 diseases and injuries 1990-2010: a systematic analysis for the Global Burden of Disease Study 2010. Lancet. 2012;380:2163-96.

7. Hourani LL, Yuan H, Bray RM. Psychosocial and lifestyle correlates of premenstrual symptoms among military women. J Womens Health. 2004;13:812-21.

8. Angst J, Sellaro R, Merikangas KR, Endicott J. The epidemiology of perimenstrual psychological symptoms. Acta Psychiatr Scand. 2001;104:110-6.

9. Derman O, Kanbur NO, Tokur TE, Kutluk T. Premenstrual syndrome and associated symptoms in adolescent girls. Eur J Obstet Gynecol Reprod Biol. 2004;116:201-6.

10. Vichnin M, Freeman EW, Lin H, Hillman J, Bui S. Premenstrual syndrome (PMS) in adolescents: severity and impairment. J Pediatr Adolesc Gynecol. 2006;19:397-402.

11. Duenas JL, Lete I, Bermejo R, Arbat A, Perez-Campos E, Martinez-Salmean J, et al. Prevalence of premenstrual syndrome and premenstrual dysphoric disorder in a representative cohort of Spanish women of fertile age. Eur J Obstet Gynecol Reprod Biol. 2011;156:72-7.

12. Wong LP, Khoo EM. Dysmenorrhea in a multiethnic population of adolescent Asian girls. Int J Gynaecol Obstet. 2010;108:139-42.

13. Bakhshani NM, Mousavi MN, Khodabandeh G. Prevalence and severity of premenstrual symptoms among Iranian female university students. J Pak Med Assoc. 2009;59:205-8.

14. Fujiwara T, Nakata R. Young Japanese college students with dysmenorrhea have high frequency of irregular menstruation and premenstrual symptoms. Open Med Inform J. 2007;1:8-11.

15. Yamamoto K, Okazaki A, Sakamoto $Y$, Funatsu M. The relationship between premenstrual symptoms, menstrual pain, irregular menstrual cycles, and psychosocial stress among Japanese college students. J Physiol Anthropol. 2009:28:129-36.

16. Kitamura M, Takeda T, Koga S, Nagase S, Yaegashi N. Relationship between premenstrual symptoms and dysmenorrhea in Japanese high school students. Arch Womens Ment Health. 2012;15:131-3.

17. lacovides S, Avidon I, Bentley A, Baker FC. Reduced quality of life when experiencing menstrual pain in women with primary dysmenorrhea. Acta Obstet Gynecol Scand. 2014;93:213-7.

18. Sahin S, Ozdemir K, Unsal A. Evaluation of premenstrual syndrome and quality of life in university students. J Pak Med Assoc. 2014;64:915-22.

19. Pinar G, Colak M, Oksuz E. Premenstrual Syndrome in Turkish college students and its effects on life quality. Sex Reprod Health. 2011;2:21-7.

20. Lete I, Duenas JL, Serrano I, Doval JL, Martinez-Salmean J, Coll C, et al. Attitudes of Spanish women toward premenstrual symptoms, premenstrual syndrome and premenstrual dysphoric disorder: results of a nationwide survey. Eur J Obstet Gynecol Reprod Biol. 2011;159:115-8.

21. Kleinstauber M, Witthoft M, Hiller W. Cognitive-behavioral and pharmacological interventions for premenstrual syndrome or premenstrual 
dysphoric disorder: a meta-analysis. J Clin Psychol Med Settings. 2012;19:308-19.

22. Matsumoto T, Ushiroyama T, Tatsumi N. Lower peripheral circulation in eumenorrheic young women with premenstrual symptoms. Biopsychosoc Med. 2007;1:8.

23. Epperson CN, Steiner M, Hartlage SA, Eriksson E, Schmidt PJ, Jones I, et al. Premenstrual dysphoric disorder: evidence for a new category for DSM-5. Am J Psychiatry. 2012;169:465-75.

24. Rozanski A, Bairey CN, Krantz DS, Friedman J, Resser KJ, Morell M, et al. Mental stress and the induction of silent myocardial ischemia in patients with coronary artery disease. N Engl J Med. 1988;318:1005-12.

25. Task Force of the European Society of Cardiology and the North American Society of Pacing and Electrophysiology. Heart rate variability. Standards of measurement, physiological interpretation, and clinical use. Eur Heart J. 1996;17:354-81

26. Usha Rani YS, Manjunath P, Desai RD. Comparative study of heart rate variability, heart rate and blood pressure in different phases of menstrual cycle in healthy young women aged 18-22 years. J Phys Pharm Adv. 2013;3:188-92.

27. Sato N, Miyake S, Akatsu J, Kumashiro M. Power spectral analysis of heart rate variability in healthy young women during the normal menstrual cycle. Psychosom Med. 1995;57:331-5.

28. Sheema UK, Sarwari KN, Malipatil BS. Influence of different phases of menstrual cycle on heart rate variability. Int J Basic Appl Med Sci. 2014:4:168-72.

29. Yildirir A, Kabakci G, Akgul E, Tokgozoglu L, Oto A. Effects of menstrual cycle on cardiac autonomic innervation as assessed by heart rate variability. Ann Noninvasive Electrocardiol. 2002;7:60-3.

30. Princi T, Parco S, Accardo A, Radillo O, De Seta F, Guaschino S. Parametric evaluation of heart rate variability during the menstrual cycle in young women. Biomed Sci Instrum. 2005;41:340-5.

31. Sato N, Miyake S. Cardiovascular reactivity to mental stress: relationship with menstrual cycle and gender. J Physiol Anthropol Appl Human Sci. 2004;23:215-23.

32. Hirshoren N, Tzoran I, Makrienko I, Edoute Y, Plawner MM, Itskovitz-Eldor J, et al. Menstrual cycle effects on the neurohumoral and autonomic nervous systems regulating the cardiovascular system. J Clin Endocrinol Metab. 2002;87:1569-75

33. Matsumoto T, Ushiroyama T, Morimura M, Moritani T, Hayashi T, Suzuki T, et al. Autonomic nervous system activity in the late luteal phase of eumenorrheic women with premenstrual symptomatology. J Psychosom Obstet Gynaecol. 2006;27:131-9.

34. Kessel B. Premenstrual syndrome. Advances in diagnosis and treatment. Obstet Gynecol Clin North Am. 2000;27:625-39.

35. Moline ML, Zendell SM. Evaluating and managing premenstrual syndrome. Medscape Womens Health. 2000;5:1.

36. Pellizzer AM, Straznicky NE, Lim S, Kamen PW, Krum H. Reduced dietary fat intake increases parasympathetic activity in healthy premenopausal women. Clin Exp Pharmacol Physiol. 1999;26:656-60.

37. Kuwahara K, Okita Y, Kouda K, Nakamura H. Effects of modern eating patterns on the cardiac autonomic nervous system in young Japanese males. J Physiol Anthropol. 2011;30:223-31.

38. Olson BR, Cartledge T, Sebring N, Defensor R, Nieman L. Short-term fasting affects luteinizing hormone secretory dynamics but not reproductive function in normal-weight sedentary women. J Clin Endocrinol Metab. 1995;80:1187-93.

39. Bergendahl M, Evans WS, Pastor C, Patel A, Iranmanesh A, Veldhuis JD. Short-term fasting suppresses leptin and (conversely) activates disorderly growth hormone secretion in midluteal phase women-a clinical research center study. J Clin Endocrinol Metab. 1999;84:883-94.

40. Bergendahl M, Iranmanesh A, Evans WS, Veldhuis JD. Short-term fasting selectively suppresses leptin pulse mass and 24-hour rhythmic leptin release in healthy midluteal phase women without disturbing leptin pulse frequency or its entropy control (pattern orderliness). J Clin Endocrinol Metab. 2000:85:207-13.

41. Ministry of Health, Labour and Welfare. National Health and Nutrition Survey in 2010. http://www.mhlw.go.jp/bunya/kenkou/eiyou/h22-houkoku.html.

42. Boardman A, Schlindwein FS, Rocha AP, Leite A. A study on the optimum order of autoregressive models for heart rate variability. Physiol Meas. 2002;23:325-36.

43. Niskanen JP, Tarvainen MP, Ranta-Aho PO, Karjalainen PA. Software for advanced HRV analysis. Comput Methods Programs Biomed. 2004;76:73-81.
44. Sloan RP, Shapiro PA, Bagiella E, Bigger Jr JT, Lo ES, Gorman JM. Relationships between circulating catecholamines and low frequency heart period variability as indices of cardiac sympathetic activity during mental stress. Psychosom Med. 1996;58:25-31.

45. Olejnik S, Algina J. Generalized eta and omega squared statistics: measures of effect size for some common research designs. Psychol Methods. 2003;8:434-47.

46. Cohen J. Statistical power analysis for the behavioral sciences. 2nd ed. Hillsdale, NJ: Lawrence Erlbaum Associates; 1988.

47. Lauer MS. Autonomic function and prognosis. Cleve Clin J Med. 2009;76:S18-22.

48. Herbert BM, Herbert C, Pollatos O, Weimer K, Enck P, Sauer H, et al. Effects of short-term food deprivation on interoceptive awareness, feelings and autonomic cardiac activity. Biol Psychol. 2012;89:71-9.

49. Chan JL, Mietus JE, Raciti PM, Goldberger AL, Mantzoros CS. Short-term fasting-induced autonomic activation and changes in catecholamine levels are not mediated by changes in leptin levels in healthy humans. Clin Endocrinol. 2007;66:49-57.

50. Hellhammer DH, Wust S, Kudielka BM. Salivary cortisol as a biomarker in stress research. Psychoneuroendocrinology. 2009;34:163-71.

51. Kirschbaum C, Pirke KM, Hellhammer DH. The Trier Social Stress Test'-a tool for investigating psychobiological stress responses in a laboratory setting. Neuropsychobiology. 1993;28:76-81.

52. Nater UM, La Marca R, Florin L, Moses A, Langhans W, Koller MM, et al. Stress-induced changes in human salivary alpha-amylase activity associations with adrenergic activity. Psychoneuroendocrinology. 2006;31:49-58

53. Filaire E, Dreux B, Massart A, Nourrit B, Rama LM, Teixeira A. Salivary alphaamylase, cortisol and chromogranin A responses to a lecture: impact of sex. Eur J Appl Physiol. 2009;106:71-7.

54. Lac G. Saliva assays in clinical and research biology. Pathol Biol. 2001:49:660-7.

55. Tanaka Y, Ishitobi Y, Maruyama Y, Kawano A, Ando T, Imanaga J, et al. Salivary alpha-amylase and cortisol responsiveness following electrical stimulation stress in panic disorder patients. Neurosci Res. 2012;73:80-4.

56. Kenny R, Dinan T, Cai G, Spencer SJ. Effects of mild calorie restriction on anxiety and hypothalamic-pituitary-adrenal axis responses to stress in the male rat. Physiol Rep. 2014;2:e00265.

57. Willette AA, Coe CL, Colman RJ, Bendlin BB, Kastman EK, Field AS, et al. Calorie restriction reduces psychological stress reactivity and its association with brain volume and microstructure in aged rhesus monkeys. Psychoneuroendocrinology. 2012;37:903-16.

58. Baker FC, Sassoon SA, Kahan T, Palaniappan L, Nicholas CL, Trinder J, et al. Perceived poor sleep quality in the absence of polysomnographic sleep disturbance in women with severe premenstrual syndrome. J Sleep Res. 2012:21:535-45.

\section{Submit your next manuscript to BioMed Central and take full advantage of:}

- Convenient online submission

- Thorough peer review

- No space constraints or color figure charges

- Immediate publication on acceptance

- Inclusion in PubMed, CAS, Scopus and Google Scholar

- Research which is freely available for redistribution 